\title{
Is There a Genetic Correlation Between General Factors of Intelligence and Personality?
}

\author{
John C. Loehlin, ${ }^{1}$ Meike Bartels, ${ }^{2}$ Dorret I. Boomsma, ${ }^{2}$ Denis Bratko, ${ }^{3}$ Nicholas G. Martin, ${ }^{4}$ \\ Robert C. Nichols, ${ }^{5}$ and Margaret J. Wright ${ }^{4}$ \\ ${ }^{1}$ Psychology Department, University of Texas, Austin, Texas, USA \\ ${ }^{2}$ Department of Biological Psychology, VU University, Amsterdam, the Netherlands \\ ${ }^{3}$ Department of Psychology, Faculty of Social Sciences and Humanities, University of Zagreb, Zagreb, Croatia \\ ${ }^{4}$ QIMR Berghofer Medical Research Institute, Brisbane, Queensland, Australia \\ 5 Jamul, CA, USA
}

\begin{abstract}
We tested a hypothesis that there is no genetic correlation between general factors of intelligence and personality, despite both having been selected for in human evolution. This was done using twin samples from Australia, the United States, the Netherlands, Great Britain, and Croatia, comprising altogether 1,748 monozygotic and 1,329 same-sex dizygotic twin pairs. Although parameters in the model-fitting differed among the twin samples, the genetic correlation between the two general factors could be set to zero, with a better fit if the U.S. sample was excepted.
\end{abstract}

Keywords: general factor of intelligence, general factor of personality, heritability, mutation-selection balance, life history theory, twins

The concept of hierarchical structure in the domains of intelligence and personality, featuring a single general factor at the top, have been controversial ever since general factors were advocated early in the 20th century by Spearman (1904) and Webb (1915). Spearman called the intelligence factor $g$, for general intelligence. Webb called the personality (or character) factor $w$, for will.

A general factor in the intelligence domain, whether labeled ' $g$ ' or 'IQ' has become assimilated into psychological thinking (e.g., Brody, 1992; Carroll, 1993; Jensen, 1998), although in practice many prefer to work further down in the hierarchy of cognitive traits, and there has been controversy about how best to carve up the ability domain fluid and crystallized abilities (Cattell, 1971); seven to nine Primary Mental Abilities (Thurstone, 1938); v:ed and k:m (Vernon, 1951). In the personality domain, the postulation of a discrete set of traits at the highest level has been the typical approach: a set of five or six broad factors is currently most popular (e.g., Costa \& McCrae, 1992; Goldberg, 1990; Saucier, 2009).

Broad personality traits are often somewhat correlated empirically, and recent years have seen the re-emergence of the idea of a general factor of personality (GFP) at the top of a personality trait hierarchy (e.g., Musek, 2007). Critics of this view have not necessarily denied the presence of a single higher-order factor, but have attributed it to measurement artifact (Bäckström et al. 2009; Pettersson et al., 2012) or declared it to be psychometrically weak (Revelle \& Wilt, 2013). However, in one study, partialing out self-esteem or social desirability measures did not greatly reduce a GFP (Erdle \& Rushton, 2011).

In defense of the substantive status of a GFP, twin studies have shown it to be substantially heritable (Loehlin \& Martin, 2011; Veselka et al., 2009), and to show relationships with measures of social effectiveness and ratings of character and integrity (Dunkel \& van der Linden, 2014; van der Linden et al., 2014). Rushton et al. (2008) proposed an evolutionary origin of the GFP: namely, that it was a result of selection on a set of traits contributing to social effectiveness and thus to reproductive success.

Evolutionary speculation has continued. On the cognitive side, Woodley (2011) proposed what he called the 'CD-IE' hypothesis to account in evolutionary terms for the presence of both general and specialized intellectual ability. CD-IE stands for 'Cognitive Differentiation-Integration

RECEIVED 14 February 2015; ACCEPTED 3 March 2015.

ADDRESS FOR CORRESPONDENCE: John C. Loehlin, Psychology Department, University of Texas, 1 University Station A8000, Austin, Texas, 78712, USA. E-mail: loehlin@utexas.edu 
Effort'. Woodley's hypothesis rests on the assumption that there are two basic dimensions underlying human development: one of general fitness and one of fast and slow life histories. On the cognitive side, general fitness takes the form of general intelligence $(g)$. Woodley posits a genetic factor G1 underlying $g$ that reflects mutation load: that is, an individual's general level of ability depends on the number of deleterious mutations he possesses (fewer such mutations $=$ higher ability). Woodley suggests that an independent factor G2 underlies the differentiation of cognitive skills, and is related to fast or slow life history (the slower the life history, the greater the opportunity for and advantage of specialized skills). In evolutionary terms, fast or slow life histories reflect the predictability of environments: in unstable environments, fast life histories with an emphasis on reproduction predominate, whereas in stable environments slow life histories featuring fewer and bettercared-for offspring are the norm. The attributes of slow life histories are not limited to specialized cognitive skills. They may include, for example, general factors of health and of personality as aspects of a 'Super-K' factor (Figueredo et al., 2007). Woodley proposes that the relevant evolutionary processes for G2 include balancing and frequencydependent selection, as opposed to the mutation-selection balance underlying G1.

Woodley carried out a meta-analysis of 10 studies in which measures of $g$ and $\mathrm{K}$ (general intelligence and slow life history) were included. In eight of the 10, the correlation between the two was non-significant, with overall a near-zero correlation of 0.023 . Based on this result and the theoretical assumptions sketched above, Woodley made a number of specific predictions, one of which was: '.. heritable intelligence should show no genetic correlations with heritable life history indicators ... when analyzed in a cross-twin cross-trait multivariate genetic analysis' (p. 239).

Doubts may be raised about this prediction, even if personality is considered a life history indictor. For example, in a large study based on genotyped individuals rather than twins (Verweij et al., 2012), the authors concluded that personality variation appeared to be more consistent with the operation of mutation-selection balance involving rare alleles than with G2 genetic mechanisms of the sort suggested by Woodley. The absence of a phenotypic correlation may also be called into question. Two studies, in each of which Woodley was one of the co-authors, obtained an appreciable correlation between measures of $g$ and GFP. One, based on the large data set of the 1960s U.S. Project Talent, reported appreciable correlations between general factors of personality and intelligence: $r=0.25$ overall; and $r$ s of $0.23,0.33$, and 0.16 within White $(N=147,355)$, Black $(N=6,533)$, and Asian $(N=999)$ subgroups, respectively (Dunkel et al., 2014a). The other, in a 1960s California prison sample $(N$ $=2,622$ to 2,668 ), obtained a correlation of 0.33 between an intelligence measure, the General Ability Test Battery, and a general personality factor from the California Psychological Inventory (Dunkel et al., 2014b).

Nevertheless, even if a phenotypic correlation exists, it remains an empirical question whether a genetic one does. It is the testing of Woodley's prediction of a zero genetic correlation between general factors of personality and intelligence that is the subject of the present article.

\section{Method}

\section{Twin Samples and Tests}

Initially, data from two twin samples were analyzed, from Australia and the United States. The results were different enough to suggest the desirability of including additional samples, so data from three other existing twin studies were added to the design. These were studies in the Netherlands, Great Britain and Croatia, originally undertaken for various purposes, that had obtained measures of ability and personality at ages roughly comparable to those in the Australian and U.S. studies.

The Australian sample was part of a larger study in which twins, mostly recruited via South East Queensland schools, were tested at ages 12, 14, and 16 (Wright \& Martin, 2004). The present sample came from the age 16 testing, at which a cognitive test battery and the Junior Eysenck Personality Questionnaire (JEPQ) were administered to the twins. Scores from a set of cognitive tests, the Multidimensional Aptitude Battery (MAB) and the JEPQ, were available for $246 \mathrm{MZ}$ and 154 same-sex DZ pairs. The general intelligence measure was obtained as the first principal factor from the five subtests of the MAB, and the personality factor from the four scales of the JEPQ. The Lie scale of the latter, although originally designed to detect faking, was included, since in a volunteer research population with no special motivation for impression management, the scale has been considered a measure of social conformity (e.g., Francis \& Montgomery, 1993; Tatalović Vorkapić, 2012).

The second sample, from the United States, consisted of twin pairs identified from among the high school juniors who took the National Merit Scholarship Qualifying Test (NMSQT) in 1962 (Loehlin \& Nichols, 1976). Those twins agreeing to participate in the research were mailed questionnaires, including the California Psychological Inventory (CPI). Scores from the CPI as well as the NMSQT were available for $490 \mathrm{MZ}$ and 317 same-sex DZ pairs. General intelligence was obtained as the first factor from the five NMSQT subtests. The general personality factor was obtained from 13 of the 18 CPI scales. The five scales not used included three scales reflecting ability or achievement, Achievement via Conformity, Achievement via Independence, and Intellectual Efficiency, omitted to minimize the risk of an artifactual correlation of the personality composite with ability, and two response bias scales, Communality and Good Impression, omitted to avoid another possible artifactual source of correlation. 
The third sample was from the Netherlands Twin Register (Van Beijsterveldt et al., 2013). From it, WAIS IQs and scores on the Dutch translation of a Five-Factor inventory (the NEO-FFI) were available (Bartels et al., 2012). The IQs were obtained at age 18 , the personality measures at average ages of 20.7 and 29.0 for two subgroups. The IQ score was taken to represent the general intelligence factor, and a general personality factor was derived from the correlations among the five scales of the NEO. Intelligence and personality factors were available for both twins of $161 \mathrm{MZ}$ and 112 same-sex DZ pairs.

The fourth sample was from the Twins' Early Development Study in Great Britain (Haworth et al., 2013). The general intelligence factor was derived from two cognitive tests administered to the twins at age 16, the Mill Hill vocabulary scale and Ravens Progressive Matrices; the personality factor was based on a Big Five inventory taken at the same age (details given in Krapohl et al., 2014 — additional online material). There were $748 \mathrm{MZ}$ and 633 same-sex DZ pairs for whom both general intelligence and general personality factors were available.

The fifth sample was from Croatia, from a twin study in which both an intelligence measure and a Big Five inventory were included (Bratko et al., 2012). The intelligence measure was the verbal subtest of a Croatian version of the General Aptitude Test Battery (GATB); the personality measure a Croatian version of the NEO-FFI, from which a general factor was extracted. Intelligence and personality factors were available for both members of $103 \mathrm{MZ}$ and 114 samesex DZ pairs. Their ages ranged from 15 to 22, with a mean of 18.6 years.

Thus, the twin samples consisted of late adolescent to young adult twins, the majority in the 16- to 19-year age range. The personality measures in the Netherlands study were obtained when the twins were somewhat older, but would still be classified as young adults.

\section{Analyses}

General factors of intelligence and personality were obtained in all five samples, in the form of first principal factors from correlations among the relevant measures over all available individuals in the sample (including different-sex and unmatched twins, if present). In two of the samples, a single measure of ability was used as an index of $g$. Correlations among the general intelligence and personality factor scores of twin 1 and twin 2 were then obtained separately in MZ and same-sex DZ subsamples, and analyzed via structural equation modeling. If the individual correlations were based on differing numbers of cases, the median number was used for the model fitting.

In short, for each of the five studies two $4 \times 4$ correlation matrices were obtained, one for $\mathrm{MZ}$ and one for $\mathrm{DZ}$ twins. The four variables in each were the factor scores of the first and second twins of a pair on $g$ and GFP, the general intelligence and personality factors.
The structural equation models represented in Figure 1 were fit to these correlation matrices, using LISREL 8.80. Degrees of freedom were adjusted for fitting to correlation matrices in multiple groups, as recommended by Neale and Cardon (1992, p. 256). An ACE model (Additive genetic variance, Common or shared family environment, individual Environment plus error) or an ADE model (Additive genetic variance, genetic Dominance, individual Environment plus error) was fit, depending on whether the DZ correlation was greater or less than half the MZ correlation. In all five samples, the DZ correlation for intelligence exceeded half the MZ correlation, so an ACE model was fit. In two of the samples, Australia and the US, this was also the case for personality, but in the other three the DZ correlation for personality was less than half the MZ correlation, suggesting the presence of non-additive genetic variance, modeled as Dominance in an ADE model (e.g., van den Berg et al., 2014).

In Figure 1, the upper circles represent latent variables capturing (respectively) genetic, shared environmental, and non-shared environmental sources of variation, with the downward arrows $h, c$, and e indicating the extent to which they influence the observed variables I1, P1, I2, and P2 in the squares below - the general intelligence and personality scores of the first and second twin. Figure 1(a) uses the ACE model for both traits. The squares of the $h, c$, and $e$ paths represent the variances of the observed variables due to the three sets of causes, thus $h^{2}$ is the heritability of intelligence or personality, $c^{2}$ its dependence on environmental influences shared by the twins, and $e^{2}$ everything else including the unique experiences of each twin and measurement error. An ADE model was used for personality in three of the samples; this is shown in Figure 1(b). D replaces $\mathrm{C}$, a path $d$ replaces the path $c$, and it is assumed the $\mathrm{C}$ of one trait is uncorrelated with the D of the other. In both models, the latent and observed variables are all standardized, that is, have variances of 1.0.

The curved lines at the top of the figures represent correlations among the latent variables that are assumed to underlie and explain the correlations among the observed variables. Thus, the correlation that Woodley hypothesizes to be zero, the genetic correlation between the intelligence and personality factors $\left(r_{\mathrm{g}}\right)$, is represented by the curved line between the first and fourth circles (or, equivalently, that between the seventh and the tenth). The correlations between the intelligence and the personality factors due to the twins' shared environments $\left(r_{\mathrm{c}}\right)$ or to environmental factors that are not shared $\left(r_{\mathrm{e}}\right)$ are also shown.

The correlations across the two twins for the same trait are assigned values specified by theory. For MZ twins, the genetic correlation is fixed at 1.0 - the twins, coming from the splitting of a single fertilized ovum, have the same genes. For DZ twins, who share on average one-half of their segregating genes, a value of 0.5 for the corresponding correlation was used. Shared environments of twins are by 
(a)

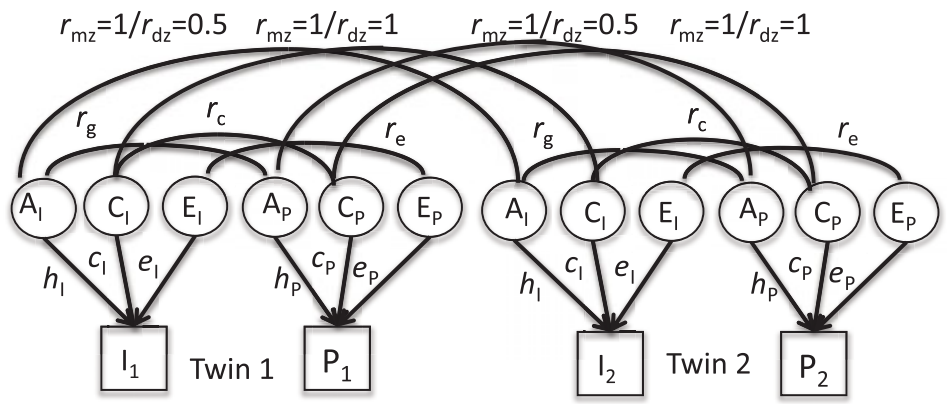

(b)

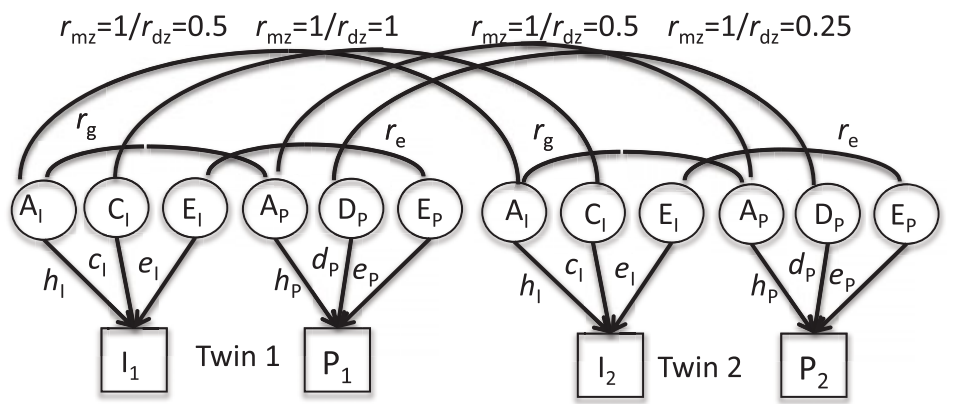

\section{FIGURE 1.}

Structural equation model fitted in five twin samples: (a) ACE models for both intelligence and personality; (b) ACE model for intelligence, ADE model for personality. Note: Observed variables, in squares = general factors of intelligence (I) and personality (P) for Twin 1 and Twin 2. Latent variables, in circles = additive effects of genes (A), common environment of twin pair (C), dominance effects of genes (D), environment unique to each twin plus measurement error, etc. (E). Paths $h, c, d, e=$ effects of latent on observed variables. Curved lines = correlations among latent variables: within each model, lower level curved lines represent within-individual correlations between intelligence and personality via genes $\left(r_{\mathrm{g}}\right)$, common environment $\left(r_{\mathrm{c}}\right)$, and non-shared environment $\left(r_{\mathrm{e}}\right)$; upper level curved lines represent cross-twin correlations for the same traits. Not shown in figure: cross-twin, cross-trait correlations: equal to $r_{g}$ for $M Z$ pairs, to $0.5 * r_{g}$ for $D Z$ pairs, equal to $r_{c}$ for both types of pairs; equal to zero for $r_{\mathrm{e}}$. All latent and observed variables standardized.

definition correlated 1.0, and unshared environments 0.0 . Genetic dominance is correlated 0.25 across DZ twins. Correlations across twins across traits, not shown in the figure to avoid clutter, are related to the within-twin across-trait correlations $r_{\mathrm{g}}$ and $r_{\mathrm{c}}$. For MZs, they are equal to $r_{\mathrm{g}}$ and $r_{c}$, since both genes and common environments are shared. The $r_{\mathrm{g}}$ for DZs is assumed equal to one-half that for MZs, the $r_{\mathrm{c}} \mathrm{s}$ for both are equal, and the $r_{\mathrm{e}} \mathrm{s}$ for both are zero - since non-shared environments, by definition, are not shared by the two twins. As noted earlier, the dominance deviations for one trait are assumed to be uncorrelated with the shared or unshared environment of the other.

\section{Results}

The loadings for the general intelligence and personality factors in the five samples are shown in Table 1, and the within- and cross-twin correlations between the two factors are shown in Table 2.

A model constrained to have equal parameters across all the 10 matrices in Table 2 had a $\chi^{2}$ of 452.84 for $53 d f$, that is, was extremely improbable. A measure of departure from a perfect fit, the Root Mean Square Error of Approximation (RMSEA) was 0.152 (after correction for $d f$ ), or almost twice the 0.08 considered to represent a reasonable fit by Browne and Cudeck (1993), and three times as large as the 0.05 they consider a close fit. However, the differences among the samples appeared to lie mainly in the paths from the latent to the observed variables, rather than the correlations. Woodley's hypothesis does not concern itself with the individual trait path values, only with the genetic correlation between the two composites. Permitting each of the five samples to have its own $h, c$ or $d$, and $e$ paths and fixing $r_{\mathrm{g}}$ to zero resulted in a $\chi^{2}$ of 44.29 for $26 d f$, and an RMSEA of 0.046, a close fit, by the Browne/Cudeck criterion. Allowing $r_{\mathrm{g}}$ to be free in the U.S. sample while remaining at zero in the other four resulted in a slightly but significantly better solution, with a $\chi^{2}$ of 39.71 for 25 $d f$ RMSEA $=0.042$. This is still a significant $\chi^{2}(p<.05)$, meaning that the fit is less than perfect, but it is a good one, as judged by RMSEA. Parameters for the five samples in this solution are shown in Figure 2.

As is evident from Figure 2, the three paths from the latent variables to the traits vary across the different samples, but they are typically all appreciable, with the exception of the near-zero $c$ path for personality in the Australian sample. The $r_{c}$ correlation for the two samples from which this correlation is estimated is fairly large, 0.68 , but it mostly 
TABLE 1

Factor Loadings for General Factors of Intelligence and Personality in Five Countries

\begin{tabular}{|c|c|c|c|}
\hline $\begin{array}{l}\text { Intelligence } \\
\text { Scale }\end{array}$ & $\begin{array}{l}\text { Factor } \\
\text { Loading }\end{array}$ & $\begin{array}{l}\text { Personality } \\
\text { Scale }\end{array}$ & $\begin{array}{l}\text { Factor } \\
\text { Loading }\end{array}$ \\
\hline \multicolumn{4}{|c|}{ Australia $(1,194 / 1,193)$} \\
\hline Information & 0.80 & Psychoticism & -0.65 \\
\hline Arithmetic & 0.66 & Extraversion & -0.13 \\
\hline Vocabulary & 0.66 & Neuroticism & -0.10 \\
\hline Spatial & 0.57 & Lie & 0.64 \\
\hline Object Assembly & 0.64 & & \\
\hline \multicolumn{4}{|c|}{ United States $(1,678 / 1,613)$} \\
\hline English usage & 0.76 & Dominance & 0.63 \\
\hline Mathematics usage & 0.73 & Capacity for status & 0.80 \\
\hline Social Science reading & 0.86 & Sociability & 0.72 \\
\hline Natural Science reading & 0.78 & Social presence & 0.61 \\
\hline \multirow{10}{*}{ Vocabulary } & 0.83 & Self-acceptance & 0.48 \\
\hline & & Sense of well-being & 0.60 \\
\hline & & Responsibility & 0.47 \\
\hline & & Socialization & 0.21 \\
\hline & & Self-control & 0.30 \\
\hline & & Tolerance & 0.73 \\
\hline & & Psychological-mindedness & 0.57 \\
\hline & & Flexibility & 0.20 \\
\hline & & Femininity & -0.10 \\
\hline & \multicolumn{3}{|c|}{ The Netherlands $(554 / 324)$} \\
\hline \multirow[t]{5}{*}{ WAIS IQ } & & Neuroticism & -0.71 \\
\hline & & Extraversion & 0.66 \\
\hline & & Openness & -0.06 \\
\hline & & Agreeableness & 0.34 \\
\hline & & Conscientiousness & 0.49 \\
\hline \multicolumn{4}{|c|}{ Great Britain $(4,287 / 4,399)$} \\
\hline Ravens & 0.82 & Neuroticism & -0.64 \\
\hline \multirow[t]{4}{*}{ Mill Hill } & 0.82 & Extraversion & 0.70 \\
\hline & & Openness & 0.44 \\
\hline & & Agreeableness & 0.60 \\
\hline & & Conscientiousness & 0.57 \\
\hline & Croatic & 668/658) & \\
\hline \multirow[t]{5}{*}{ GATB verbal } & & Neuroticism & -0.62 \\
\hline & & Extraversion & 0.44 \\
\hline & & Openness & -0.20 \\
\hline & & Agreeableness & 0.42 \\
\hline & & Conscientiousness & 0.46 \\
\hline
\end{tabular}

Note: Numbers of individuals for the intelligence and personality factor analyses are given after country title.

depends on the U.S. sample - it is weakly determined in the Australian sample because of the near-zero $c$ path so its generality may be questionable. The correlations due to unshared environment vary. They are in the 0.02 to 0.08 range except for the U.S. and Australian samples, where they are 0.19 and 0.39 , respectively.

\section{Discussion}

Fitting path models involving genetic and environmental correlations to data from five twin samples from the U.S., Europe and Australia gave results reasonably consistent with Woodley's hypothesis that the genetic correlation between general factors of intelligence and personality is zero.

Least consistent with the Woodley hypothesis was the U.S. National Merit sample. Allowing its $r_{\mathrm{g}}$ parameter to be estimated separately from the other samples led to a modest but significant reduction in overall chi square. The National
Merit sample was different from the other samples in several respects. It came from an earlier period - the data were gathered in the early 1960s, whereas the other samples were measured much more recently, in some cases nearly 50 years later. Its estimate of $g$ came from a restricted range of ability, and to a greater degree reflected performance in areas of academic subject matter. The restriction in ability range ought to lower, rather than raise, the correlation with other measures (such as personality); the inclusion of academic achievement variance would have an uncertain effect - it might raise the correlation with conscientiousness, for example, but lower that with extraversion. There also conceivably could be a difference between twins in the U.S. and Europe/Australia. Two of these three alternatives are consistent with the substantial personality-intelligence correlation from the Project Talent data (Dunkel et al., 2014a) - based on a sample also from U.S. high schools and also from the 1960s, a sample much broader in 
TABLE 2

General Factor Score Correlations Within and Across Twin Pairs for Intelligence and Personality, to Which Models Were Fit

\begin{tabular}{|c|c|c|c|c|c|c|c|c|}
\hline \multirow[b]{2}{*}{ Factor score } & \multicolumn{4}{|c|}{$\mathrm{MZ}$ pairs } & \multicolumn{4}{|c|}{ DZ pairs } \\
\hline & 11 & P1 & 12 & P2 & 11 & P1 & 12 & P2 \\
\hline \multicolumn{9}{|c|}{ Australia (246/154) } \\
\hline Intelligence, Twin1 & 1.00 & & & & 1.00 & & & \\
\hline Personality, Twin 1 & -0.05 & 1.00 & & & 0.08 & 1.00 & & \\
\hline Intelligence, Twin2 & 0.84 & -0.08 & 1.00 & & 0.53 & 0.08 & 1.00 & \\
\hline Personality, Twin 2 & -0.03 & 0.58 & -0.01 & 1.00 & -0.02 & 0.35 & 0.08 & 1.00 \\
\hline Intelligence, Twin1 & 1.00 & & & & 1.00 & & & \\
\hline Personality, Twin1 & 0.36 & 1.00 & & & 0.32 & 1.00 & & \\
\hline Intelligence, Twin2 & 0.89 & 0.33 & 1.00 & & 0.65 & 0.24 & 1.00 & \\
\hline Personality, Twin 2 & 0.32 & 0.60 & 0.37 & 1.00 & 0.21 & 0.39 & 0.32 & 1.00 \\
\hline \multicolumn{9}{|c|}{ The Netherlands $(161 / 112)$} \\
\hline Intelligence, Twin1 & 1.00 & & & & 1.00 & & & \\
\hline Personality, Twin1 & 0.05 & 1.00 & & & 0.19 & 1.00 & & \\
\hline Personality, Twin 2 & 0.02 & 0.52 & 0.04 & 1.00 & 0.09 & 0.18 & 0.14 & 1.00 \\
\hline \multicolumn{9}{|c|}{ Great Britain (748/632) } \\
\hline Intelligence, Twin1 & 1.00 & & & & 1.00 & & & \\
\hline Personality, Twin1 & 0.12 & 1.00 & & & 0.00 & 1.00 & & \\
\hline Intelligence, Twin2 & 0.60 & 0.03 & 1.00 & & 0.36 & 0.00 & 1.00 & \\
\hline Personality, Twin 2 & 0.05 & 0.39 & 0.00 & 1.00 & 0.06 & 0.17 & 0.05 & 1.00 \\
\hline \multicolumn{9}{|c|}{ Croatia $(103 / 114)$} \\
\hline Intelligence, Twin1 & 1.00 & & & & 1.00 & & & \\
\hline Personality, Twin1 & 0.01 & 1.00 & & & -0.12 & 1.00 & & \\
\hline Intelligence, Twin2 & 0.78 & -0.07 & 1.00 & & 0.62 & 0.08 & 1.00 & \\
\hline Personality, Twin 2 & -0.05 & 0.67 & -0.08 & 1.00 & -0.16 & 0.25 & -0.06 & 1.00 \\
\hline
\end{tabular}

Note: Numbers of MZ and DZ pairs given after country title. I1 = Intelligence, Twin 1; P1 = Personality, Twin 1; I2= Intelligence, Twin 2; P2 = Personality, Twin 2.

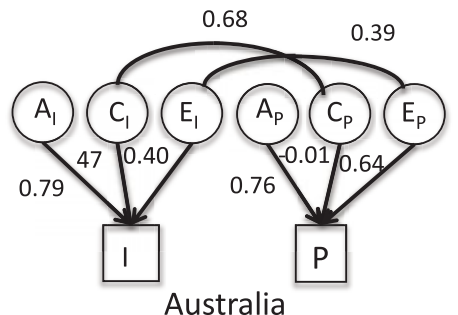

Australia

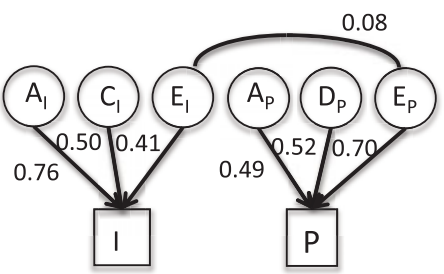

The Netherlands

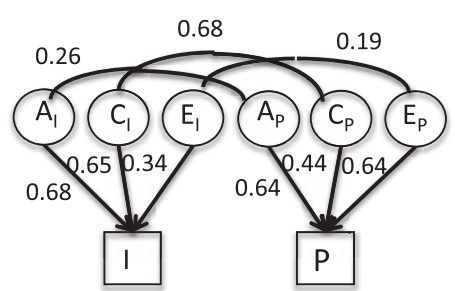

US National Merit

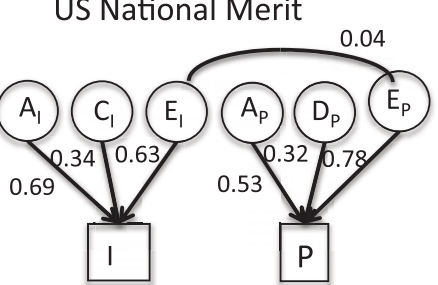

Great Britain

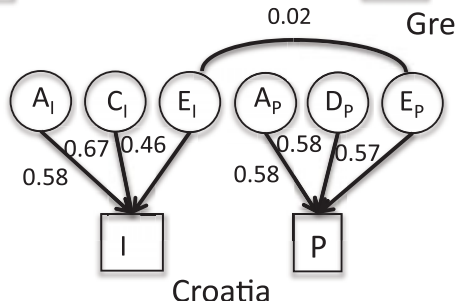

FIGURE 2.

Parameters for models fit to twin data from five countries, with $r_{g}$ fixed to zero for all but U.S. sample. 
ability range than the National Merit sample, as well as from a restricted-range California prison sample also from the U.S. and from the 1960s (Dunkel et al., 2014b).

The parameters in the remaining four twin samples were clearly not identical, but the differences appeared to lie largely in the path values. That is, the samples differed in the paths from the genes and shared and unshared environments to the general factors rather than in the relations between the latter. This might partly reflect differences in the tests used, although differences for similar tests are notable - for example, Openness is related positively to the general personality factor in Great Britain, negatively in Croatia, and close to zero in the Netherlands. In a U.S. adult sample, general personality factors derived individually from seven different personality inventories had substantial loadings on a common general factor (ranging from 0.53 to 0.81 ; Loehlin, 2012). These inventories included the NEO and the CPI used in the present study, although not the JEPQ. An eighth inventory, the HEXACO, had nearzero loadings on the common factor. This exception suggests that the common general factor was not simply a result of evaluative bias, or the like, which should apply equally to the HEXACO, but a matter of substance. The added Modesty/Humility dimension of the HEXACO apparently combined with Agreeableness to swing the first factor of this inventory away from the rest - with either of these two dimensions removed, the general factor of the HEXACO aligned with the others, with loadings of 0.62 or 0.67 on the common factor (Loehlin, 2012).

As to samples, the present ones did not differ greatly in age, but were recruited in different ways, and were, of course, from different countries.

Lack of association between general factors does not rule out genetic and environmental correlations at the level of individual traits. For example, in the study from the Netherlands, genetic correlations between Agreeableness and IQ and Openness and IQ were present at the trait level (Bartels et al., 2012), although in the present analysis there was not a significant genetic contribution at the level of the general factor. There also were specific genetic associations between Openness and IQ and Extraversion and IQ in the Croatian sample (Bratko et al., 2012).

One limitation of the present study is that the modeling involved only twins, so some confounding between shared environment and non-additive genetic variance may be present. More complex approaches, such as twin-family designs, could help discriminate these.

Although the present results are consistent with Woodley's prediction, how clearly do they support his distinction between general factors based on life history speed and on general fitness? Here, matters are a little murkier. The argument that slow life histories should lead to more differentiation of cognitive skills seems plausible, but one might wonder whether a similar argument might not apply to personality: that is, that slow life histories might lead to greater differentiation among personality traits, whereas general fitness might affect a general factor of personality. The absence of a substantial genetic correlation between the two general factors is one empirical argument against this view, but further clarification of the underlying theoretical relationships would seem desirable. For example, a particular evolutionary mechanism, mutation-selection balance, acting separately in two independent sets of genes, could leave the respective general factors uncorrelated unless selection on them occurred jointly.

In conclusion, it should be recognized that the finding of a zero (or near-zero) genetic correlation between general factors of intelligence and personality may be given various interpretations. One would be that general factors of intelligence and personality exist, but their evolutionary history and biological substrates are uncorrelated. Another would be that the GFP represents, at least in part, measurement biases such as self-esteem or halo effects, and, if the former, the genetic factors underlying these are uncorrelated with those underlying ability (not an altogether trivial assumption). Another view might be that the finding is not very interesting, because a more useful way of approaching personality (and perhaps ability as well) is at a level well below that of a single general factor - although to this third view one must surely add the qualification that the most useful level will depend upon one's purposes.

A fourth possibility is to take seriously the apparent phenotypic difference between the U.S. samples from the 1960s and more recent European and Australian samples, and postulate that some underlying process has changed. Not the effects of evolution, presumably, over such a short time span, but something in biology or culture or measurement affecting the relationship between general factors of intelligence and personality. The present data do not reveal what that something might be, but further investigation with other data sets spanning the period involved could clarify, first, whether the difference truly exists, and if it does, what changes underlie it.

\section{Acknowledgments}

We are grateful to Robert Plomin and Eva Krapohl for supplying the data from the Twins Early Development Study in Great Britain. For helpful comments on an earlier version of this article, we are grateful to David Buss, and also to Elliot Tucker-Drob, Paige Harden, and graduate students in their seminar — Frank Mann in particular.

\section{References}

Bäckström, M., Björklund, F., \& Larsson, M. R. (2009). Five-factor inventories have a major factor related to social desirability which can be reduced by framing items neutrally. Journal of Research in Personality, 43, 335-344. 
Bartels, M., van Weegen, F. I., Beijsterveldt, C. E. M., Carlier, M., Polderman, T. J. C., Hoekstra, R. A., ... Boomsma, D. I. (2012). The five factor model of personality and intelligence: A twin study of the relationships between the two constructs. Personality and Individual Differences, 53, 368-373.

Bratko, D., Butkovic, A., Vukasovic, T., Chamorro-Premuzic, T., \& von Stumm, S. (2012). Cognitive ability, selfassessed intelligence, and personality: Common genetic but independent environmental aetiologies. Intelligence, 40, 91-99.

Brody, N. (1992). Intelligence (2nd ed.), San Diego, CA: Academic Press.

Browne, M. W., \& Cudeck, R. (1993). Alternative ways of assessing model fit. In K. A. Bollen \& J. S. Long (Eds.), Testing structural equation models (pp. 136-162). Thousand Oaks, CA: Sage.

Carroll, J. B. (1993). Human cognitive abilities: A survey of factor-analytic studies. Cambridge, UK: Cambridge University Press.

Cattell, R. B. (1971). Abilities: Their structure, growth, and action. Boston: Houghton Mifflin.

Costa, P. T., Jr, \& McCrae, R. R. (1992). NEO PI-R professional manual. Odessa, FL: Psychological Assessment Resources.

Dunkel, C. S., \& van der Linden, D. (2014). Evidence for the general factor of personality as social-effectiveness. Personality and Individual Differences, 64, 147-151.

Dunkel, C. S., Cabeza De Baca, T., Woodley, M. A., \& Fernandes, H. B. F. (2014a). The general factor of personality and general intelligence: Testing hypotheses from differential- $K$, life history theory, and strategic differentiation-integration effort. Personality and Individual Differences, 61-62, 13-17.

Dunkel, C. S., van der Linden, D., Beaver, K. M., \& Woodley, M. A. (2014b). Using a prison sample to assess the association between the general factor of personality and general intelligence. Intelligence, 47, 72-82.

Erdle, S., \& Rushton, J. P. (2011). Does self-esteem or social desirability account for a general factor of personality (GFP) in the Big Five? Personality and Individual Differences, 50, 1152-1154.

Figueredo, A. J., Vásquez, G., Brumbach, B. H., \& Schneider, S. M. R. (2007). The K-factor, covitality, and personality: A psychometric test of life history theory. Human Nature, 18, 47-73.

Francis, L. J., \& Montgomery, A. (1993). Personality and school-related attitudes among 11- to 16-yearold girls. Personality and Individual Differences, 14, 647-654.

Goldberg, L. R. (1990). An alternative 'description of personality': The Big-Five factor structure. Journal of Personality and Social Psychology, 59, 1216-1229.

Haworth, C. M. A., Davis, O. S. P., \& Plomin, R. (2013). Twins early development study (TEDS). A genetically sensitive investigation of cognitive and behavioral development from childhood to young adulthood. Twin Research and Human Genetics, 16, 117-125.
Jensen, A. R. (1998). The g factor: The science of mental ability. Westport, CT: Praeger.

Krapohl, E., Rimfeld, K., Shakeshaft, N. G., Trzaskowski, M., McMillan, A., Pingault, J.-B., ... Plomin, R. (2014). The high heritability of educational achievement reflects many genetically influenced traits, not just intelligence. Proceedings of the National Academy of Sciences of the United States of America, 111, 15273-15278.

Loehlin, J. C. (2012). How general across inventories is a general factor of personality? Journal of Research in Personality, $46,258-263$.

Loehlin, J. C., \& Martin, N. G. (2011). The general factor of personality: Questions and elaborations. Journal of Research in Personality, 45, 44-49.

Loehlin, J. C., \& Nichols, R. C. (1976). Heredity, environment and personality. Austin, TX: University of Texas Press.

Musek, J. (2007). A general factor of personality: Evidence for the Big One in the five-factor model. Journal of Research in Personality, 41, 1213-1233.

Neale, M. C., \& Cardon, L. R. (1992). Methodology for genetic studies of twins and families. Dordrecht: the Netherlands.

Pettersson, E., Turkheimer, E., Horn, E. E., \& Menatti, A. R. (2012). The general factor of personality and evaluation. European Journal of Personality, 26, 292-302.

Revelle, W., \& Wilt, J. (2013). The general factor of personality: A general critique. Journal of Research in Personality, 47, 493-504.

Rushton, J. P., Bons, T. A., \& Hur, Y.-M. (2008). The genetics and evolution of the general factor of personality. Journal of Research in Personality, 42, 1173-1185.

Saucier, G. (2009). Recurrent personality dimensions in inclusive lexical studies: Indications for a Big Six structure. Journal of Personality, 77, 1577-1614.

Spearman, C. (1904). General intelligence, objectively determined and measured. American Journal of Psychology, 15, 201-293.

Tatalović Vorkapić, S. (2012). The significance of preschool teacher's personality in early childhood education: Analysis of Eysenck's and Big Five dimensions of personality. International Journal of Psychology and Behavioral Sciences, 2, 28-37.

Thurstone, L. L. (1938). Primary mental abilities. Chicago: University of Chicago Press.

Van Beijsterveldt, C. E. M., Groen-Blokhuis, M., Hottenga, J. J., Franić, S., Hudziak, J. J., Lamb, D., ... Boomsma, D. I. (2013). The Young Netherlands Twin Register (YNTR): Longitudinal twin and family studies in over 70,000 children. Twin Research and Human Genetics, 16, 252-267.

van den Berg, S. M., de Moor, M. H., McGue, M., Pettersson, E., Terracciano, A., Verweij, K. J., ... Boomsma, D. I. (2014). Harmonization of neuroticism and extraversion phenotypes across inventories and cohorts in the genetics of personality consortium: An application of Item Response Theory. Behavior Genetics, 44, 295-313.

van der Linden, D., te Nijenhuis, J., Cremers, M., van de Ven, C., \& van der Heijden-Lek, K. (2014). The general factor of personality (GFP) relates to other ratings of character and 
integrity: Two validity studies in personnel selection and training of the Dutch armed forces. International Journal of Selection and Assessment, 22, 261-271.

Vernon, P. E. (1951). The structure of human abilities. London: Methuen \& Co.

Verweij, K. J. H., Yang, J., Lahti, J., Veijola, J., Hintsanen, M., Pulkki-Råback, L., . . . Zeitsch, B. P. (2012). Maintenance of genetic variation in personality: Testing evolutionary models by estimating heritability due to common causal variants and investigating the effect of distant inbreeding. Evolution, $66,3238-3251$.

Veselka, L., Schermer, J. A., Petrides, K. V., \& Vernon, P. A. (2009). Evidence for a heritable general factor of personality in two studies. Twin Research and Human Genetics, 12, 254260.

Webb, E. (1915). Character and intelligence. British Journal of Psychology Monograph Supplements, No. 3.

Woodley, M. A. (2011). The cognitive differentiationintegration effect hypothesis: A synthesis between the fitness indicator and life history models of human intelligence. Review of General Psychology, 15, $228-245$.

Wright, M. J. \& Martin, N. G. (2004). Brisbane Adolescent Twin Study: Outline of study methods and research projects. Australian Journal of Psychology, 26, 65-78. 